\title{
REASONS WHY SELF-DIRECTED LEARNING IS IMPORTANT IN SOUTH AFRICA DURING THE COVID-19 PANDEMIC
}

\author{
S. C. Mahlaba
}

\author{
Research Unit Self-Directed Learning \\ Mathematics Education \\ North West University \\ Mafikeng Campus, South Africa \\ e-mail: 32535856@nwu.ac.za / https://orcid.org/0000-0001-6153-3917
}

\section{ABSTRACT}

We live in unprecedented times and are bombarded with various changes to normality and everyday usual business. Recently, the COVID-19 pandemic has changed the face of university education in South Africa and the world. The move towards remote teaching has denied medical students to do their practical work in hospitals, science students to access their laboratories where they conduct their experiments as part of their coursework and has denied students a chance to gain information in university libraries. This has had effects on both students' and lecturers' progress in the academic year and has called for an abrupt change in the way they view teaching and learning. The aim of this article is to highlight the significance of being a self-directed learner during the COVID-19 pandemic and to answer the following question: Why is self-directed learning important in South Africa during the COVID-19 pandemic? To answer this question, I discuss the challenges faced globally during the COVID-19 pandemic, and I focus on the challenges higher education institutions face with regard to remote teaching. Thereafter, I discuss self-directed learning and its importance in students and teachers with the aim of highlighting what self-directed learners can do when faced with the abrupt changes brought about by COVID-19. Lastly, recommendations are made to highlight that higher education institutions should prepare learners to be self-directed in their learning in order to prepare them for such abrupt changes in the future. Keywords: self-directed learning, COVID-19, remote teaching

\section{INTRODUCTION AND PROBLEM STATEMENT}

Nowadays we live in an uncertain and unprecedented world with abrupt global vicissitudes in all spheres of life. The fast-approaching Fourth Industrial Revolution (4IR) is one change that is still sparking global political debates in both economic and educational arenas. Furthermore, the 4IR has shaken the educational arena globally: questions are raised in respect of the type of education that should be provided to children in order to be competent in the 4IR. Furthermore, the 4IR has changed the role of teachers ${ }^{1}$ in the classroom, as the possibility of placing teacherassistant robots in classrooms is looming globally (Reich-Stiebert and Eyssel 2016; Sharkey 
2016). Such changes are, nonetheless, gradual, unlike changes that require instant specialised responses (e.g. pandemics). Recently, a respiratory system-related infectious disease coronavirus 2 (SARS-CoV-2) or COVID-19 - has been declared a pandemic (Remuzzi and Remuzzi 2020; Green 2020). This pandemic has induced countrywide lockdowns which have affected trade industries, businesses and even education sectors globally. Due to the lockdown in South Africa, all non-essential workers had to work from home and students were also forced to be quarantined in their homes to fight the spread. This has caused a scare not only to people's health but also to the quality of education offered to students as well as economies globally.

\section{CHANGES BROUGHT ABOUT BY THE COVID-19 PANDEMIC IN SOUTH AFRICA}

After the World Health Organization (WHO) declared COVID-19 a pandemic, the South African president declared a state of disaster and announced a shutdown of the country. Only essential services were permitted to work. Global research has highlighted challenges related to healthcare, economy and socio-economic status brought about by lockdowns.

\section{Challenges related to healthcare, economy and socio-economic status}

Studies have shown that being confined to one's home may contribute to the rise in obesity (Rundle et al. 2020) and might exacerbate existing cases (Pietrobelli et al. 2020), which might increase COVID-19-related deaths (Dietz and Santos-Burgoa 2020). Furthermore, practising social distancing through nationwide lockdowns may increase psychological instabilities. As people are forced to self-isolate and quarantine themselves at their homes, their mental and emotional health can be negatively affected, causing illnesses such as post-traumatic stress disorder, anxiety, and depression, amongst others (Galea, Merchant and Lurie 2020; Venkatesh and Edirappuli 2020; Brooks et al. 2020). School closure may exacerbate mental illness for children and adolescents already living with mental illnesses due to the lack of exposure to support material to which they usually have access in schools (Lee 2020). The increased level of exposure to the same people (i.e., family members) and being alone for prolonged periods cause boredom; as a result, most people may become fixated on social media. This can have negative repercussions, since high exposure to social media is related to mental problems, especially anxiety and depression (Gao et al. 2020). Furthermore, high exposure to social media may lead to misinformation about the COVID-19 pandemic, which may lead to panic and severe health problems (Lee 2020; Wang et al. 2020; Perloff 2014; Best, Manktelow and Taylor 2014) due to the rapid spread of fake news on social media (Tandoc, Lim and Ling 2018; Depoux et al. 2020) and people's susceptibility to fake news due to the lack of reasoning and critical thinking skills (Pennycook and Rand 2019). Moreover, the loss of income that may arise 
as a consequence of the COVID-19 pandemic may increase the pressure on breadwinners to care for their families, and the loss of free school meals may exacerbated this pressure, which may also contribute to long-term mental problems (Douglas et al. 2020; Van Lancker and Parolin 2020) and may increase cases of domestic abuse (Lee 2020).

The risks are even higher in South Africa, as most of the population are socioeconomically disadvantaged and live in poor physical conditions with unhygienic lifestyles. The Trends in Mathematics and Science Study in South Africa shows that there is a drastic gap in children's literacy due to different socio-economic backgrounds (Reddy et al. 2015), and school closures due to the COVID-19 pandemic may exacerbate this problem (Van Lancker and Parolin 2020; Armitage and Nellums 2020). Furthermore, while most schools do not have clear guidelines on measures to practise social distancing when needed (Uscher-Pines et al. 2018), school closures may overwhelm healthcare systems (Bayham and Fenichel 2020). However, this practice prevents far less COVID-19 infections and deaths compared to other social distancing methods that show promise in curbing the spread of COVID-19 (Viner et al. 2020; Prem et al. 2020). While these observations have been made in other countries, the effects of the COVID-19 pandemic also apply to South Africa, and this pandemic can be devastating if not managed properly.

\section{Challenges faced by South African universities and education during the COVID-19 pandemic}

Schools and universities were shut down to curb the spread of COVID-19, as these are public spaces with high movement and concentrated populations. This meant that learners had to stay at home. Teachers had to deliberate and plan on how they could best teach their students whilst at home. Higher education institutions and the Department of Basic Education (DoBE) held several meetings with experts to mitigate the best solution to continue teaching and learning in the midst of the COVID-19 pandemic. These meetings yielded the conclusion that remote teaching (or eLearning) was the best solution to keep educational activities going during the lockdown. In response to this change, universities resorted to remote teaching and learning to salvage the academic year. This meant that students and lecturers had to rely on their own Internet access in their remote environments. Due to realities faced by some learners and lecturers who live in social conditions that make home schooling, remote teaching and learning difficult (Van Lancker and Parolin 2020), remote teaching as a strategy adopted by most universities came with drastic challenges to universities. One of the challenges was the issue of students and lecturers not having enough data to access material needed for remote learning. Some universities negotiated with network providers and were able to secure data deals, which 
were distributed to students and lecturers. Despite these data deals, however, some learners still report that they are struggling with connectivity given that their location does not have a stable network access and some of them do not have gadgets that support Internet access. To help even further in this regard, some universities have procured and distributed gadgets to students without gadgets to access the Internet and they have provided paper-based material to students who do not have a stable network assess.

Furthermore, assessments of student learning had to be performed remotely. The remote handling of assessments has jeopardised the quality of university graduates (Mahabeer and Pirtheepal 2019), however: media in South Africa reported that students in two of the top universities in the country were sharing answers to online texts. Almaiah, Al-Khasawneh and Althunibat (2020) highlight empirical reasons from previous studies as well as their most recent study for the failure of remote teaching and provide practical suggestions for how failure in this regard can be avoided.

These current abrupt changes have taught me a few things about the nature of teaching and learning in South Africa. Firstly, we should not keep our students permanently dependent on us (as teachers) for their learning, because we will not always be there to provide learning. Secondly, during this COVID-19 pandemic, students have entered uncharted territory in their education where they have been given more responsibility for their learning than usual. This has been a shock to many students. According to Knowles (1975), this is a tragic repercussion of not being self-directed. Thirdly, I believe that the COVID-19 pandemic has revealed that Knowles' thoughts and views were not adventurous but pointed to a future in which most of us are now living. Fourthly, guided by the old paradigm, gatherings in lecture halls were the norm for achieving teaching and learning goals in different courses at different universities which reached the designated audience. However, the lockdown induced by the COVID-19 pandemic has changed the way we communicate and has forced people to move their communication to online platforms, consequently changing the face of teaching and learning. Fifthly, the digital transformations brought about by the 4IR has proved to be useful in expanding the communication platforms where information is communicated to reach the global masses. Furthermore, the COVID-19 pandemic has shown just how imperative these technological transformations are in the 21 st century. In fact, studies globally have shown that the incorporation of technology (specifically online technology) is the best method of salvaging the academic year during the COVID-19 pandemic (Chick et al. 2020). Lastly, as the teacher is not physically present during remote teaching to monitor and direct learning, students are afforded opportunities and are challenged to take initiative and responsibility for their learning. This compels students to be self-directed in their remote learning. 
Self-directed learning (SDL) has received an enormous amount of interest in educational research. Even though these research efforts on SDL initially focused mainly on adult education, recent literature has expanded this phenomenon to high school and university students. $^{2}$ This is because this phenomenon has recently been seen in a new light - even though its foundations are within adult education, its applications are vast. The focus of such recent research on higher- and basic education is mainly on how teachers can develop SDL skills in students because of the benefits of SDL. Self-directed learning is, amongst others, a good predictor of academic performance (Cazan and Schiopca 2014; Khiat 2017; Tekkol and Demirel 2018), equips learners with skills that go beyond classroom practice and, in most cases, emulates professional practice (Pedley and Arber 1997; Gibbons 2002), enhances problemsolving and reflection skills (Hewitt-Taylor 2001), is a tool for innovation (Servant-Miklos and Noordegraaf-Eelens 2019; Geng, Law and Niu 2019) and increases motivation to learn (Brookfield 1985). However, success in being self-directed in learning depends mainly on one's readiness, which can be measured using the various scales of SDL readiness (Guglielmino 1977; Cheng et al. 2010; Fisher, King and Tague 2001; Williamson 2007). Promoting SDL in students is currently a global imperative given that self-directed learners are sought after in the 21 st century (Du Toit-Brits 2019; Guglielmino 2013) and they are more successful in achieving their learning goals. Furthermore, given the recent developments brought about by the COVID19 pandemic - that is, the introduction of remote teaching and learning as the new norm in many countries - self-directedness in students is tested, and it is one skill that can help students thrive in their academic progress and development during this pandemic. The move towards remote teaching and learning transforms the context of teaching and learning from the usual lecture room interactions to online teaching and learning platforms. Context is an important factor that contributes to the self-directedness of students (Candy 1991; De Beer 2019). Hence, the COVID-19 pandemic's forcing of remote education calls for students to be self-directed in their learning. In line with this, in this article, I discuss benefits of being a self-directed learner during the COVID-19 pandemic with the aim of answering the following research question: Why is SDL important in South Africa during the COVID-19 pandemic?

\section{SELF-DIRECTED LEARNING AND ITS BENEFITS FOR EDUCATION}

\section{What is self-directed learning?}

In this article, I apply Knowles' (1975) widely accepted definition of SDL to explicate my conceptualisation of thereof and its significance during the COVID-19 pandemic. Knowles defines SDL as follows: 
"Self-directed learning describes a process in which individuals take initiative, with or without the help of others, in diagnosing their learning needs, formulating learning goals, identifying human and material resources for learning, choosing and implementing appropriate learning strategies, and evaluating learning outcomes" (Knowles 1975).

In the literature on SDL, terms such as self-education, autonomous learning, independent learning, self-initiated learning and others have been used interchangeably to refer to SDL due to the subtle and inconsistent differences that exist between these terms and SDL (Saks and Leijen 2014; Oddi 1987; Dehnad et al. 2014). However, these terms differ from SDL in that they refer to learning as something that occurs in isolation, whereas SDL portrays learning as a collective activity done in collaboration with others (Knowles 1975).

Furthermore, the concepts of SDL and self-regulated learning (SRL) are also used interchangeably in the literature (Saks and Leijen 2014; Gandomkar and Sandars 2018). Although SDL and SRL share similarities, the marginal difference between the two is the fact that, in SDL, the tasks and the environment are designed by the "learner", whereas in SRL, they are designed by the "teacher" (Gandomkar and Sandars 2018; Saks and Leijen 2014; Loyens, Magda and Rikers 2008). In particular, "SDL describes the general approach to learning adopted by a learner, whereas SRL has a specific focus on the key learning processes in relation to a clearly defined task" (Gandomkar and Sandars 2018). SRL involves temporarily specified processes, strategies or responses that students need to constructively initiate and regulate (Zimmerman 1989), hence, a self-regulated learner might stop being self-regulated after achieving certain learning goals. Another distinction is that self-directed learners are always self-regulated in their learning, while the opposite is not true (Gandomkar and Sandars 2018). SDL is usually concerned with both the learning environment that allows for the promotion of SDL skills and learners' ability and readiness to be self-directed in their learning (Loyens et al. 2008). SRL is just one component and a "characteristic" of SDL. Hence, self-regulation is one approach self-directed learners can use to achieve their learning goals. The development of SDL skills in a person relies heavily on another self-directed person (Pearce 2019) who gives appropriate opportunities for one to develop SDL skills (Gijbels et al. 2012). In other words, persons who are not self-directed in their learning cannot help others who are not self-directed to develop SDL skills.

Teaching SDL involves shifts in thinking about teaching and learning from teacherdirected to student-directed learning. This shift involves transforming the decisions about the teaching and learning process and especially the role of the teacher in the learning process. In teacher-directed learning, the decisions about content, goals, assessment and learning strategies are the responsibility of the teacher and the student is supposed to follow instructions from the 
teacher, whereas in SDL, decisions about these processes rest with the learner (Gibbons 2002). This transformation involves transforming the assessment from focusing on memorisation and reproduction of facts with feedback focused on giving correct answers to participative active assessments where students actively reflect on individual and peer assessment practices (Lubbe and Mentz 2019; Jennifer 2013). The replacement of teachers as main presenters of content with technology was predicted a while ago, and this is nowadays seen during the COVID-19 pandemic where different institutions present content on online learning platforms (Gibbons 2002).

\section{A glimpse of self-directed learners}

There might be a glitch in one aspect of Knowles' conceptualisation of SDL. Knowles mentions that self-directed learners take the initiative to formulate their own learning goals they want to achieve at the end of their learning trajectory. Perhaps, I have used the word "end" inconsiderably here, considering that the process of learning in SDL does not end, but in my conceptualisation of the previous sentence, the word "end" is used to refer to the achievement of the learning goal. However, how does one set one's own learning goals in higher education institutions that already have each course set up with certain learning goals that need to be achieved by students in order to graduate? For example, in the calculus course I lecture, students should develop proficiency in both differential and integral calculus. Furthermore, the assessments used in these courses usually test knowledge retention and procedural application without assessing the proficiency in using this knowledge to solve problems or ask questions that require synthesis of knowledge. Answering this question might seem biased and subjective for many, since I would give my viewpoint on how students can set their own learning goals in such situations. What is evident in the workplace, where most SDL is based, is that employees need to solve a certain problem (that is, the learning goal). Higher education institution students can view this learning goal as developing proficiency in both integral and differential calculus and begin by, for example, attempting to find the solution to the differential equation

$$
y^{\prime}+\frac{2 y}{x}=\frac{y^{3}}{x^{2}} .
$$

Finding the solution to this differential equation is part of the broader goal of studying calculus, but achieving the goal of finding the solution to this particular differential equation can be approached as an SDL activity. Students can diagnose their learning needs, in this case, identifying what they know and what they need to know about solving differential equations. Once they have done so, they can then set their mini-goals of achieving competency in what 
they do not know about solving differential equations. They can continue in their trajectory of developing competency in their deficient knowledge of solving differential equations in a selfdirected way, and they can evaluate the achievement of their learning goals by solving the differential equation and other related ones. In this way, they take initiative and responsibility for their learning by choosing their efficient learning methods without the lecturer having to tell them how differential equations are solved. The achievement of such mini-goals in a selfdirected way encapsulates the achievement of the broader goals of the course in a self-directed way. ${ }^{3}$ In this way, we can eradicate the assumption that students come to university ready to learn mathematical content at different levels and contexts, because if self-directed learners start by patching up their weaknesses in achieving the learning goals, they strengthen their learning. These weaknesses might not be apparent to lecturers, or students might be agitated to share them in the lecture room in the presence of other students.

In the subheading, I used the phrase "self-directed learners", which, in the context of this study, refers to learners in basic education, higher education institutions, teachers, lecturers and the general public. Self-directed learners are aware of the significance of possessing appropriate content knowledge and can efficiently apply this knowledge in different problem-solving situations (Lieberman and Linn 1991). Content knowledge is important not only in solving problems in a particular domain but also in teaching that domain (Ball, Thames and Phelps 2008). Self-directed learners have the ability to integrate different knowledge domains, which allows them to evaluate their weaknesses, and are able to locate appropriate sources to strengthen these weaknesses. As the responsibility for learning rests with them, self-directed learners use this given autonomy as motivation to continue with learning tasks, in the process choosing which content is worth learning to achieve certain set goals, and they usually relate with a certain learning strategy that benefits them the most in their learning (Slevin and Lavery 1991; Raemdonck, Gijbels and Van Groen 2014). These learners continue in the quest of learning for their intrinsic joy and realisation of the need to do so for their own development (Raemdonck et al. 2014). The knowledge self-directed learners possess is a product of their learning efforts rather than a permanent plague of some authoritative voice instilled by the teacher in the classroom. They are responsible for this content knowledge and they continually regulate this knowledge. Learner autonomy further allows them to produce more original thoughts about certain phenomena or original ${ }^{4}$ solutions to certain problems, which has been associated with creativity (Torrance and Mourad 1978; Guglielmino and Roberts 1992; Morris 2020) because of SDL's focus on the learning environment, which is considered important in promoting creative ideas (Mishra and Henriksen 2018). This is in line with mathematical practice that has linked the production of original solutions (or thought) to mathematical 
problems to creativity (Leikin and Pitta-Pantazi 2013; Leikin 2009; Sriraman, Yaftian and Lee 2011; Meissner 2015). In the workplace, creativity allows employees to be free and autonomous in their work (Lemmetty and Collin 2020).

Typically, self-directed learners build a wide repertoire of problem-solving strategies through reflecting after the processes of "entry", "attack" and "review" during problem-solving (Polya 1973; Burton 1984). Such learners are proficient in their manipulation and application of mathematical symbols and are well versed in the rules of applying different procedures for different purposes in a variety of mathematical problem-solving contexts. They systematically coordinate their approach to a problem, identifying the key parameters involved in the solution and understanding the interrelationships between them (Lieberman and Linn 1991). Selfdirected learners use their preferred learning styles at their own pace to achieve set goals (Slevin and Lavery 1991). With the powerful tool of possessing a repertoire of problem-solving strategies, self-directed mathematics learners are more likely to produce multiple solutions to mathematical problems. Self-directed learners are usually proficient in using the information at their disposal effectively to solve problems because they are aware of their thinking and cognisant of the exact time for reflecting and potentially using a different approach to a problem (Schoenfeld 1987; Schoenfeld 1992; Flavell 1979). Self-directed learners turn their errors into informative restoration points for reflection, and once successful in solving a problem, they are able to extrapolate the problem-solving strategy (Lieberman and Linn 1991).

Another significant and usually neglected characteristic of self-directed learners is that they are also interdependent (Nah 1999). SDL is usually measured as an individual characteristic (which it is), but recent studies have shown that SDL has components of teamwork and collaboration (Mentz and Van Zyl 2018; Slavin 1991). However, in the definition of SDL provided by Knowles, he mentions "identifying human and material resources for learning" (Knowles 1975). This implies that self-directed learners can seek help from fellow colleagues or knowledgeable others to accomplish their learning goals, hence interdependence. The interdependence of self-directed learners on other people is perhaps the driving force for research looking into the effects of cooperative learning (Mentz and Van Zyl 2018; Johnson and Johnson 2019; Breed and Bailey 2018; Mentz and van Zyl 2016; Lee, Tsai, Chai and Koh 2014). In particular, during cooperative learning, learners are involved in activities and decision-making reminiscent of SDL (Mentz and Van Zyl 2018).

Table 1 summarises some of the characteristics of self-directed learners. This is not an exhaustive list but the most renowned ones in the field. 
Table 1: Some characteristics of self-directed learners

\begin{tabular}{|l|l|l|}
\hline They are self-motivated to learn. & They are autonomous. & Monitor their individual learning. \\
\hline $\begin{array}{l}\text { They can evaluate the achievement of } \\
\text { their own learning goals. }\end{array}$ & $\begin{array}{l}\text { They set individualised learning } \\
\text { strategies to achieve their set } \\
\text { learning goals. }\end{array}$ & $\begin{array}{l}\text { Clear individual goals for } \\
\text { themselves. }\end{array}$ \\
\hline $\begin{array}{l}\text { Open and willing to learning new } \\
\text { things. }\end{array}$ & Curiosity & $\begin{array}{l}\text { They are intrinsically motivated to } \\
\text { learn }\end{array}$ \\
\hline They value learning. & $\begin{array}{l}\text { They possess self-control of } \\
\text { their learning. }\end{array}$ & They take initiative to learn. \\
\hline $\begin{array}{l}\text { They identify resources for their } \\
\text { learning. }\end{array}$ & They are creative. & They are resilient. \\
\hline
\end{tabular}

\section{Reasons SDL is important}

Now I have come to the crux of this article, the points presented answer the research question posed earlier. Existing research on SDL usually addresses issues of developing SDL skills in the ever-changing world and compartmentalising the role of the teacher and the student in this process. Given the recent challenges and anomalies brought about by COVID-19, especially in the educational and public domains, we see people relying mainly on their individual capabilities to normalise their lives. For example, for many students, the practice of remote learning is foreign to them, but due to the COVID-19 pandemic, they find themselves having to rely on remote learning to continue with their studies. This anomaly is also true for many teachers in both basic and higher education institutions who find themselves having to rely on remote teaching to perform their teaching and learning duties. This has put pressure on both teachers and learners and, in most cases, they regard the practices of teaching and learning as laborious tasks. ${ }^{5}$ The main challenge lies in the fact that this situation was not predicted, hence, no remote teaching training was provided to teachers who now are expected to implement remote teaching. Even though remote teaching has been recognised as an important approach to education for the development of 21st-century skills (Siu Cheung et al. 2014; Pantazis 2002) and has been proven to be effective in supporting students' academic performance (Dai and Xia 2020), it is fraught with numerous challenges, some of which are difficult to alleviate (Almaiah et al. 2020). The alleviation of such challenges calls for the transformation approach to learning where students are given more responsibility for their learning.

\section{The importance of SDL in students}

Self-directed learners are driven by various intrinsic rewards, such as self-esteem, interest, the joy of discovery and achieving satisfaction (Knowles 1975). Self-direction enables learners to take the initiative to work independently to achieve individually set learning goals through resilience, discipline, perseverance and commitment (Jossberger et al. 2018). Self-directed learners are ethical: they do not cheat in assessments, because their aim is to not merely pass a certain module but to obtain extensive conceptual understanding of the subject which will allow 
them to prosper in the future if faced with similar problems. Hence, being a self-directed learner means taking initiative to learn for one's intrinsic joy of discovery and development and preparing oneself for the ever-changing world. SDL allows for successful and efficient problem-solving, as evidence suggests that problem-based learners are self-directed in their learning (Jossberger et al. 2018; Blumberg 2000; Abdullah, Mohd-Isa and Samsudin 2019). These learners are successful because their resilience, discipline and commitment usually pay off in finding solutions to problems, and they are efficient because they are able to compute multiple solutions to a multi-solution problem using their reflective ability and are able to choose the most elegant one to present as their final solution. Self-directed learners tend to have long-term memory retention of what they have learnt, and they can use this knowledge in various scenarios of learning and problem-solving (Knowles 1975; Gureckis and Markant 2012). Self-directed learners are fluid to change: they adapt to new developments quicker and tend to devise new plans that are in line with new developments. Upon realising that remote learning is their new norm, self-directed learners would diagnose their weaknesses in dealing with remote learning and take the initiative to convert their weaknesses into strengths to maximise their learning in the new normal. As part of taking their own initiative, self-directed learners can further identify resources that would help them cope with remote learning and ensure that they acquire extensive learning experiences of the subject matter. These learners can plan their learning tasks so that they meet deadlines set by teachers, while ensuring that they produce work that displays quality in assessment tasks. Most importantly, self-directed learners see learning as a way of living, a way in which they can survive and thrive in society and the most efficient way for their development. They regard any change in their normal learning environment as a challenge to adapt and continue learning.

\section{The importance of SDL in teachers}

I recognise that lecturers are key into students' learning and development of skills they will need to survive in the 21 st century. However, I adopt the view that, as much as lecturers are important in this process, students themselves should be responsible for their learning and should transform their role from that of being knowledge receivers to being knowledge constructors. Most lecturers still think their role is to transmit content to students and regard the level of absorption and reproduction of content as learning. In the classroom, they play the role of being an expert who has mastered the content and is ready to transmit it to students. However, self-directed teachers emancipate themselves from this practice to rather be a facilitator of learning. Instead of worrying about what content needs to be covered, they worry about making the classroom environment conducive to diagnosing learning needs, planning and executing learning plans to achieve learning goals (Knowles 1975). Instead of being authoritative, 
teachers who value SDL empower learners to direct themselves in their learning through motivating them and showing them their ability to direct their own learning (Gibbons 2002). Teachers who value self-direction in their classrooms give learners the responsibility to manage and direct their learning and they act as facilitators or "procedural guides" of the learning process (Knowles 1975). They help learners find their learning passion in learning and challenge them to pursue this passion on their own, which enables them to engage with proficient and struggling students (Gibbons 2002). They also empower learners to focus on learning worthwhile knowledge and skills they do not possess in order to be successful in achieving set learning goals (Gureckis and Markant 2012). Just like their students, self-directed teachers are fluid to change; they position themselves both in their students' and their profession's shoes. In the case of remote teaching, self-directed teachers are able to modify their assessment strategies so as to assess higher-order thinking skills and include questions that assess students' synthesis of knowledge instead of their ability to retain and recall knowledge.

\section{CONCLUDING REMARKS}

In his conclusion highlighting the significance of SDL, Malcom Knowles stated that SDL should be practice for "survival" in a rapidly changing world, not only of individuals but also of the human race (Knowles 1975). He later posited that SDL is a "prerequisite" for living in this ever-changing world. However, most research on university students has shown that they are not ready for SDL (Alharbi 2018; Mentz and Van Zyl 2018) and a number of studies have revealed that even some interventions do not increase learners' self-directedness to a considerable level (Van der Westhuizen and Golightly 2019). Given the benefits of SDL, especially during the COVID-19 pandemic, teaching and learning at higher institutions should, nonetheless, focus on developing students' SDL readiness.

As mentioned earlier in the discussion of SDL and higher education institutions, the COVID-19 pandemic has given learners a chance to take responsibility for their learning by diagnosing their learning needs, setting their own learning goals and executing individualised methods of learning to achieve identified learning goals and evaluate their own learning. Given the challenges students face in remote learning environments, higher education institutions should provide them with a stable Internet connection, technological gadgets and stable remote teaching and learning systems (Almaiah et al. 2020), which some South African universities have been doing thus far. Finally, teacher development programmes need to find a way to work with teachers rather than working on teachers. This would increase teachers' voice as the most experienced voice in the discourse of teaching and teaching practice. This means that teachers need to be positioned as self-directed learners in their professional development who are continually reflecting on their past practices, with or without the help of other teachers, to better 
their future classroom practice (Smith 2017).

\section{NOTES}

1. The words teachers and lecturers are used interchangeably in this article to refer to qualified professionals responsible for overseeing the development of students in educational institutions.

2. However, in Knowles' original conceptualisation of SDL, he describes the difference between pedagogy and andragogy as different mindsets that can be adopted by teachers, whether teaching children or adults. He mentions that a teacher who believes in pedagogy would teach pedagogically, whether teaching children or adult, and a teacher who believes in andragogy would teach adults or children andragogically (Knowles 1975).

3. Ibid. speak of learning in a self-directed way as the accomplishment of "inquiry tasks" which, in the end, sum up to the achievement of a broader learning goal.

4. Original in this sense is used to mean thought products of the learner that come from intrinsic interrogation and assessment of a scenario without influence from other people.

5. I was talking to a friend of mine the other day, and she mentioned how stressed she was with remote teaching. She was mainly concerned with the fact that remote teaching has distanced her from her family due to recording lessons in a quiet environment and having to attend to Google classrooms and other remote teaching activities with her limited skills in technology.

\section{REFERENCES}

Abdullah, J., W. N. Mohd-Isa and M. A. Samsudin. 2019. Virtual reality to improve group work skill and self-directed learning in problem-based learning narratives. Virtual Reality 23(4): 461-471.

Alharbi, H. A. 2018. Readiness for self-directed learning: How bridging and traditional nursing students differs? Nurse Education Today 61: 231-234.

Almaiah, M. A., A. Al-Khasawneh and A. Althunibat. 2020. Exploring the critical challenges and factors influencing the E-learning system usage during COVID-19 pandemic. Education and Information Technologies, 1-20.

Armitage, R. and L. B. Nellums. 2020. Considering inequalities in the school closure response to COVID-19. The Lancet Global Health 8(5): e644.

Ball, D. L., M. H. Thames and G. Phelps. 2008. Content knowledge for teaching:What makes it special? Journal of Teacher Education 59(5): 389-407.

Bayham, J. and E. P. Fenichel. 2020. Impact of school closures for COVID-19 on the US health-care workforce and net mortality: A modelling study. The Lancet Public Health 5(5): e271-e278.

Best, P., R. Manktelow and B. Taylor. 2014. Online communication, social media and adolescent wellbeing: A systematic narrative review. Children and Youth Services Review 41: 27-36.

Blumberg, P. 2000. Evaluating the evidence that problem-based learners are self-directd learners: A review of the literature. In Problem-based learning: A research perspective on learning interactions, ed. D. H. Evensen and C. E. Hmelo. Mahwah, New Jersey: Lawrence Erlbaum Associates Publishers.

Breed, B. and R. Bailey. 2018. The influence of a metacognitive approach to cooperative pair problemsolving on self-direction in learning. TD : The Journal for Transdisciplinary Research in Southern Africa 14(1): 1-11.

Brookfield, S. 1985. Self-directed learning: A critical review of research. New Directions for Adult and Continuing Education 1985(25): 5-16.

Brooks, S. K., R. K. Webster, L. E. Smith, L. Woodland, S. Wessely, N. Greenberg and G. J. Rubin. 2020. The psychological impact of quarantine and how to reduce it: Rapid review of the evidence. The Lancet 395(10227): 912-920.

Burton, L. 1984. Mathematical thinking: The struggle for meaning. Journal for Research in 
Mathematics Education 15(1): 35-49.

Candy, P. C. 1991. Self-direction for lifelong learning, San Fransiscoe: Jossey-Bass.

Cazan, A.-M. and B.-A. Schiopca. 2014. Self-directed learning, personality traits and academic achievement. Procedia - Social and Behavioral Sciences 127: 640-644.

Cheng, S.-F., C.-L. Kuo, K.-C. Lin and J. Lee-Hsieh. 2010. Development and preliminary testing of a self-rating instrument to measure self-directed learning ability of nursing students. International Journal of Nursing Studies 47(9): 1152-1158.

Chick, R. C., G. T. Clifton, K. M. Peace, B. W. Propper, D. F. Hale, A. A. Alseidi and T. J. Vreeland. 2020. Using technology to maintain the education of residents during the COVID-19 pandemic. Journal of Surgical Education 77(4): 729-732.

Dai, D. and X. Xia. 2020. Whether the school self-developed e-Learning platform is more conducive to learning during the COVID-19 pandemic? Best Edivence of Chinese Education 5(1): 569-580.

De Beer, J. 2019. The importance of context for self-directed learning. In Self-directed learning for the 21st century: Implications for higher education, ed. E. Mentz, J. de Beer and R. Bailey. Durbanville, Capetown: AOSIS.

Dehnad, A., F. Afsharian, F. Hosseini, S. K. S. Arabshahi and S. Bigdeli. 2014. Pursuing a definition of self-directed learning in literature from 2000-2012. Procedia - Social and Behavioral Sciences 116: 5184-5187.

Depoux, A., S. Martin, E. Karafillakis, R. Preet, A. Wilder-Smith and H. Larson. 2020. The pandemic of social media panic travels faster than the COVID-19 outbreak. Journal of Travel Medicine 27(3).

Dietz, W. and C. Santos-Burgoa. 2020. Obesity and its implications for COVID-19 mortality. Obesity 28(6): 1005-1005.

Douglas, M., S. V. Katikireddi, M. Taulbut, M. McKee and G. McCartney. 2020. Mitigating the wider health effects of covid-19 pandemic response. BMJ 369: m1557.

Du Toit-Brits, C. 2019. A focus on self-directed learning: The role that educators' expectations play in the enhancement of students' self-directedness. South African Journal of Education 39: 1-11.

Fisher, M., J. King and G. Tague. 2001. Development of a self-directed learning readiness scale for nursing education. Nurse Education Today 21(7): 516-525.

Flavell, J. H. 1979. Metacognition and cognitive monitoring: A new area of cognitive-developmental inquiry. American Psychologist 34(10): 906-911.

Galea, S., R. M. Merchant and N. Lurie. 2020. The mental health consequences of COVID-19 and physical distancing: The need for prevention and early intervention. JAMA Internal Medicine 180(6): 817-818.

Gandomkar, R. and J. Sandars. 2018. Clearing the confusion about self-directed learning and selfregulated learning. Medical Teacher 40(8): 862-863.

Gao, J., P. Zheng, Y. Jia, H. Chen, Y. Mao, S. Chen, Y. Wang, H. Fiu and J. Dai. 2020. Mental health problems and social media exposure during COVID-19 outbreak. PLos One 15(4): 1-10.

Geng, S., K. M. Y. Law and B. Niu. 2019. Investigating self-directed learning and technology readiness in blending learning environment. International Journal of Educational Technology in Higher Education 16(1): 17.

Gibbons, M. 2002. The self-directed learning handbook: Challenging adolescent students to excel. San Francisco, CA: Jossey-Bass.

Gijbels, D., I. Raemdonck, D. Vervecken and J. Herck. 2012. Understanding work-related learning: The case of ICT workers. Journal of Workplace Learning 24: 416-429.

Green, M. S. 2020. Did the hesitancy in declaring COVID-19 a pandemic reflect a need to redefine the term? The Lancet 395(10229): 1034-1035.

Guglielmino, L. M. 1977. Development of the self-directed learning readiness scale. University of 
Georgia.

Guglielmino, L. M. 2013. The case for promoting self-directed learning in formal educational institutions. SA-eDUC Journal 10(2): 1-18.

Guglielmino, P. J. and D. G. Roberts. 1992. A comparison of self-directed learning readiness in U.S. and Hong Kong samples and the implications for job performance. Human Resource Development Quarterly 3(3): 261-271.

Gureckis, T. M. and D. B. Markant. 2012. Self-directed learning: A cognitive and computational perspective. Perspectives on Psychological Science 7(5): 464-481.

Hewitt-Taylor, J. 2001. Self-directed learning: Views of teachers and students. Journal of Advanced Nursing 36: 496-504.

Jennifer, G. 2013. Assessment for learning: A wider (classroom-researched) perspective is important for formative assessment and self-directed learning in general practice. Education for Primary Care 24(2): 93-96.

Johnson, D. W. and R. T. Johnson. 2019. The impact of cooperative learning on self-directed learning. In Self-directed learning for the 21st century: Implications for higher education, ed. E. Mentz, J. de Beer and R. Bailey. Durbanville, Cape Town: AOSIS.

Jossberger, H., S. Brand-Gruwel, M. W. L. van de Wiel and H. Boshuizen. 2018. Learning in workplace simulations in vocational education: A student perspective. Vocations and Learning 11(2): 179204.

Khiat, H. 2017. Academic performance and the practice of self-directed learning: The adult student perspective. Journal of Further and Higher Education 41(1): 44-59.

Knowles, M. S. 1975. Self-directed learning: A guide for learners and teachers. Englewood Cliffs, NJ: Cambridge Adult Education.

Lee, J. 2020. Mental health effects of school closures during COVID-19. The Lancet. Child \& Adolescent Health 4(6): 421-421.

Lee, K., P.-S. Tsai, C. S. Chai and J. H. L. Koh. 2014. Students' perceptions of self-directed learning and collaborative learning with and without technology. Journal of Computer Assisted Learning 30(5): 425-437.

Leikin, R. 2009. Exploring mathematical creativity using multiple solution tasks. In Creativity in mathematics and the education of gifted students, ed. R. Leikin, A. Berman and B. Koichu. Brill | Sense.

Leikin, R. and D. Pitta-Pantazi. 2013. Creativity and mathematics education: The state of the art. ZDM 45(2): 159-166.

Lemmetty, S. and K. Collin. 2020. Self-directed learning as a practice of workplace learning: Interpretative repertoires of self-directed learning in ICT work. Vocations and Learning 13(1): $47-70$.

Lieberman, D. A. and M. C. Linn. 1991. Learning to learn revisited. Journal of Research on Computing in Education 23(3): 373-395.

Loyens, S. M. M., J. Magda and R. M. J. P. Rikers. 2008. Self-directed learning in problem-based learning and its relationships with self-regulated learning. Educational Psychology Review 20(4): 411-427.

Lubbe, A. and E. Mentz. 2019. Participative assessment practices and its contribution to the development of sefl-directed learning skills. In Self-directed learning for the 21st century: Implications for higher education, ed. E. Mentz, J. de Beer and R. Bailey. Cape Town: AOSIS.

Mahabeer, P. and T. Pirtheepal. 2019. Assessment, plagiarism and its effect on academic integrity: Experiences of academics at a university in South Africa. South African Journal of Science 115: $1-8$.

Meissner, H. 2015. Creativity in mathematics education. In 12th International Congress on Mathematical Education, ed. S. J. Cho, 591-592. Cham. Springer International Publishing. 
Mentz, E. and S. van Zyl. 2016. Introducing cooperative learning: Students' attictudes towards learning and the implications for self-directed learning. Journal of Education 64(1): 79-109.

Mentz, E. and S. van Zyl, S. 2018. The impact of cooperative learning on self-directed learning abilities in the computer applications technology class. International Journal of Lifelong Education 37(4): $482-494$.

Mishra, P. and D. Henriksen. 2018. The architecture of creative learning environments. In Creativity, technology \& education: Exploring their convergence, ed. P. Mishra and D. Henriksen. Cham: Springer International Publishing.

Morris, T. H. 2020. Creativity through self-directed learning: Three distinct dimensions of teacher support. International Journal of Lifelong Education: 1-11.

Nah, Y. 1999. Can a self-directed learner be independent, autonomous and interdependent?: Implications for practice. Adult Learning 11(1): 18-25.

Oddi, L. F. 1987. Perspectives on self-directed learning. Adult Education Quarterly 38(1): 21-31.

Pantazis, C. 2002. Maximizing e-learning to train the 21st century workforce. Public Personnel Management 31(1): 21-26.

Pearce, D. 2019. A model for developing competent and self-directed tradespeople. International Journal of Training Research 17(1): 50-64.

Pedley, G. E. and A. Arber. 1997. Nursing students' response to self-directed learning: An evaluation of a learning process applying Jarvis' framework. Journal of Advanced Nursing 25(2): 405-11.

Pennycook, G. and D. G. Rand. 2019. Lazy, not biased: Susceptibility to partisan fake news is better explained by lack of reasoning than by motivated reasoning. Cognition 188: 39-50.

Perloff, R. M. 2014. Social media effects on young women's body image concerns: Theoretical perspectives and an agenda for research. Sex Roles 71(11): 363-377.

Pietrobelli, A., L. Pecoraro, A. Ferruzzi, M. Heo, M. Faith, T. Zoller, F. Antoniazzi, G. Piacentini, S. N. Fearnbach and S. B. Heymsfield. 2020. Effects of COVID-19 lockdown on lifestyle behaviors in children with obesity living in Verona, Italy: A longitudinal study. Obesity (Silver Spring) 28(8): 1382-1385.

Polya, G. 1973. How to solve it: A new aspect of mathematical method. Princeton, NJ: Princeton University Press.

Prem, K., Y. Liu, T. W. Russell, A. J. Kucharski, R. M. Eggo, N. Davies, S. Flasche, S. Clifford, C. A. B. Pearson, J. D. Munday, S. Abbott, H. Gibbs, A. Rosello, B. J. Quilty, T. Jombart, F. Sun, C. Diamond, A. Gimma, K. van Zandvoort, S. Funk, C. I. Jarvis, W. J. Edmunds, N. I. Bosse, J. Hellewell, M. Jit and P. Klepac. 2020. The effect of control strategies to reduce social mixing on outcomes of the COVID-19 epidemic in Wuhan, China: A modelling study. The Lancet Public Health 5(5): e261-e270.

Raemdonck, I., D. Gijbels and W. van Groen. 2014. The influence of job characteristics and self-directed learning orientation on workplace learning. International Journal of Training and Development 18(3): 188-203.

Reddy, V., M. Visser, L. Winnaar, F. Arends, A. Juan, C. Prinsloo and K. Sidale. 2015. TIMSS 2015: Highlights of mathematics and science achievement of grade 9 South African Learners, ed, V. Reddy, M. Visser, L. Winnaar, F. Arends, A. Juan, C. Prinsloo and K. Sidale. Pretoria.

Reich-Stiebert, N. and F. Eyssel. 2016. Robots in the classroom: What teachers think about teaching and learning with education robots. In 8th International Conference, 2016, ed. A. Agah, J.-J. Cabibihan, M. A. Salichs and H. He, 671-680. Cham. Springer International Publishing.

Remuzzi, A. and G. Remuzzi. 2020. COVID-19 and Italy: What next? The Lancet 395(10231): 12251228.

Rundle, A. G., Y. Park, J. B. Herbstman, E. W. Kinsey and Y. C. Wang. 2020. COVID-19 related school closings and risk of weight gain among children. Obesity 28(6): 1008-1009.

Saks, K. and Ä. Leijen. 2014. Distinguishing self-directed and self-regulated learning and measuring 
them in the e-learning context. Procedia - Social and Behavioral Sciences 112: 190-198.

Schoenfeld, A. H. 1987. What's all the fuss about metacognition. In Cognitive science and mathematics education, ed. A. H. Schoenfeld. Hillsdale, New Jersy: Lawrence Erlbaum Associates, Publishers.

Schoenfeld, A. H. 1992. Learning to think mathematically: Problem solving, metacognition, and sense making in mathematics. In Handbook for research on mathematics teaching and learning, ed. D. Grouws. New York: Macmillan.

Servant-Miklos, V. and L. Noordegraaf-Eelens. 2019. Toward social-transformative education: An ontological critique of self-directed learning. Critical Studies in Education: 1-17.

Sharkey, A. J. C. 2016. Should we welcome robot teachers? Ethics and Information Technology 18(4): 283-297.

Siu Cheung, K., C. Tak-Wai, G. Patrick, H. Ulrich, H. Ronghuai, Chee Kit L. Kinshuk, M. Marcelo, N. Cathleen, N. Miguel, S. Mike, S. Wing Mui Winnie, S. Elliot and Y. Shengquan. 2014. E-learning in school education in the coming 10 years for developing 21 st century skills: Critical research issues and policy implications. Journal of Educational Technology \& Society 17(1): 70-78.

Slavin, R. E. 1991. Educational psychology: Theory into practice. Englewood CLiffs, NJ: Prentice Hall.

Slevin, O. D. A. and M. C. Lavery. 1991. Self-directed learning and student supervision. Nurse Education Today 11(5): 368-377.

Smith, K. 2017. Teachers as self-directed learners: Active positioning through professional learning,. Singapore: Springer.

Sriraman, B., N. Yaftian and K. H. Lee. 2011. Mathematical creativity and mathematics education: A derivative of existing research. In The elements of creativity and giftedness in mathematics, ed. B. Sriraman and K. Lee. Brill | Sense.

Tandoc, E. C., Z. W. Lim and R. Ling. 2018. Defining "fake news". Digital Journalism 6(2): 137-153.

Tekkol, İ. A. and M. Demirel. 2018. An investigation of self-directed learning skills of undergraduate students. Frontiers in Psychology 9(2324): 1-14.

Torrance, E. P. and S. Mourad. 1978. Some creativity and style of learning and thinking correlates of Guglielmino's self-directed learning readiness scale. Psychological Reports 43(3 suppl): 11671171.

Uscher-Pines, L., H. L. Schwartz, F. Ahmed, Y. Zheteyeva, E. Meza, G. Baker and A. Uzicanin. 2018. School practices to promote social distancing in K-12 schools: Review of influenza pandemic policies and practices. BMC Public Health 18(1): 406.

Van der Westhuizen, C. and A. Golightly. 2019. Developing self-directed learning skills of Geography student teachers through online problem-based learning designs. In Self-directed learning for the 21st century: Implications for higher education, ed. E. Mentz, J. de Beer and R. Bailey. Cape Town: AOSIS.

Van Lancker, W. and Z. Parolin. 2020. COVID-19, school closures, and child poverty: A social crisis in the making. The Lancet Public Health 5(5): e243-e244.

Venkatesh, A. and S. Edirappuli. 2020. Social distancing in covid-19: What are the mental health implications? BMJ 369: m1379.

Viner, R. M., S. J. Russell, H. Croker, J. Packer, J. Ward, C. Stansfield, O. Mytton, C. Bonell and R. Booy. 2020. School closure and management practices during coronavirus outbreaks including COVID-19: A rapid systematic review. The Lancet Child \& Adolescent Health 4(5): 397-404.

Wang, G., Y. Zhang, J. Zhao, J. Zhang and F. Jiang. 2020. Mitigate the effects of home confinement on children during the COVID-19 outbreak. The Lancet 395(10228): 945-947.

Williamson, S. N. 2007. Development of a self-rating scale of self-directed learning. Nurse Researcher 14(2): 66-83.

Zimmerman, B. J. 1989. Models of self-regulated learning and academic achievement. In Self-regulated learning and academic achievement: Theory, research, and practice, ed. B. J. Zimmerman and D. H. Schunk. New York, NY: Springer New York. 